\title{
Xylopic acid-amodiaquine and xylopic acid-artesunate combinations are effective in managing malaria in Plasmodium berghei-infected mice
}

Silas Acheampong Osei ${ }^{1,2}$, Robert Peter Biney ${ }^{2,3}$, Ernest Obese ${ }^{2,3}$, Mary Atta-Panyi Agbenyeku1, Isaac Yaw Attah ${ }^{1,2}$, Elvis Ofori Ameyaw ${ }^{1,2^{*}}$ (i) and Johnson Nyarko Boampong ${ }^{1,2}$

\begin{abstract}
Background: Evidence of Plasmodium resistance to some of the current anti-malarial agents makes it imperative to search for newer and effective drugs to combat malaria. Therefore, this study evaluated whether the co-administrations of xylopic acid-amodiaquine and xylopic acid-artesunate combinations will produce a synergistic anti-malarial effect.

Methods: Antiplasmodial effect of xylopic acid (XA: 3, 10, 30, 100, $150 \mathrm{mg} \mathrm{kg}^{-1}$ ), artesunate (ART: 1, 2, 4, 8, $16 \mathrm{mg} \mathrm{kg}^{-1}$ ), and amodiaquine (AQ: 1.25, 2.5, 5, 10, $20 \mathrm{mg} \mathrm{kg}^{-1}$ ) were evaluated in Plasmodium berghei (strain ANKA)infected mice to determine respective $\mathrm{ED}_{50} \mathrm{~s}$. Artemether/lumefantrine was used as the positive control. XA/ART and $X A / A Q$ were subsequently administered in a fixed-dose combination of their $\mathrm{ED}_{50} \mathrm{~S}(1: 1)$ and the combination fractions of their $\mathrm{ED}_{50} \mathrm{~S}\left(1 / 2,1 / 4,1 / 8,1 / 16\right.$, and 1/32) to determine the experimental $\mathrm{ED}_{50} \mathrm{~S}\left(\mathrm{Z}_{\text {exp }}\right)$. An isobologram was constructed to determine the nature of the interaction between XA/ART, and XA/AQ combinations by comparing $Z_{\text {exp }}$ with the theoretical $\mathrm{ED}_{50}\left(Z_{\text {add }}\right)$. Bodyweight and 30-day survival post-treatment were additionally recorded.

Results: $\mathrm{ED}_{50} \mathrm{~s}$ for $\mathrm{XA}, \mathrm{ART}$, and $\mathrm{AQ}$ were $9.0 \pm 3.2,1.61 \pm 0.6$, and $3.1 \pm 0.8 \mathrm{mg} \mathrm{kg}^{-1}$, respectively. The $Z_{\text {add }} Z_{\text {exp }}$, and interaction index for XA/ART co-administration was $5.3 \pm 2.61,1.98 \pm 0.25$, and 0.37 , respectively while that of XA/AQ were $6.05 \pm 2.0,1.69 \pm 0.42$, and 0.28 , respectively. The $Z_{\text {exp }}$ for both combination therapies lay significantly $(p<0.001)$ below the additive isoboles showing XA acts synergistically with both ART and AQ in clearing the parasites. High doses of XA/ART combination significantly $(p<0.05)$ increased the survival days of infected mice with a mean hazard ratio of 0.40 while all the XA/AQ combination doses showed a significant $(p<0.05)$ increase in the survival days of infected mice with a mean hazard ratio of 0.27 similar to AL. Both XA/ART and XA/AQ combined treatments significantly $(p<0.05)$ reduced weight loss.
\end{abstract}

Conclusion: Xylopic acid co-administration with either artesunate or amodiaquine produces a synergistic anti-plasmodial effect in mice infected with P. berghei.

Keywords: Antimalarial drugs, Combination therapies, Isobolographic analysis, Xylopic acid, Artesunate, Amodiaquine, Synergism, Plasmodium berghei

*Correspondence: elvisameyaw@gmail.com

${ }^{1}$ Department of Biomedical Sciences, School of Allied Health Sciences, University of Cape Coast, Cape Coast, Ghana

Full list of author information is available at the end of the article

\section{Background}

Regardless of the efforts put in place in the twenty-first century to eradicate the staggering toll of malaria on human health, the global burden of the disease remains,

c) The Author(s) 2021. This article is licensed under a Creative Commons Attribution 4.0 International License, which permits use, sharing, adaptation, distribution and reproduction in any medium or format, as long as you give appropriate credit to the original author(s) and the source, provide a link to the Creative Commons licence, and indicate if changes were made. The images or other third party material in this article are included in the article's Creative Commons licence, unless indicated otherwise in a credit line to the material. If material is not included in the article's Creative Commons licence and your intended use is not permitted by statutory regulation or exceeds the permitted use, you will need to obtain permission directly from the copyright holder. To view a copy of this licence, visit http://creativeco mmons.org/licenses/by/4.0/. The Creative Commons Public Domain Dedication waiver (http://creativecommons.org/publicdomain/ zero/1.0/) applies to the data made available in this article, unless otherwise stated in a credit line to the data. 
especially, in several tropical countries. The World Health Organization (WHO) estimates that $40 \%$ of the world's population is susceptible to malaria infections [1]. A recent report indicates that 228 million cases of malaria occurred in 2018, which resulted in 405,000 deaths, mostly in sub-Saharan Africa [2]. About 93\% (213 million) of the cases in 2018 were recorded in the WHO African Region. Ghana and Nigeria are the two countries among the 10 highest-burden countries in Africa, which recorded an increase in malaria cases from 2017 to 2018. Children under five years succumb to the devastating effects of the disease, accounting for 272,000 (67\%) of all malaria deaths worldwide [2]. The incidence rate and the death toll of malaria on children make the disease a major global infectious disease.

Cinchona alkaloids (quinine and quinidine) and artemisinin derivatives (artesunate, artemether, and arteether) are the two classes of medicines available for the treatment of severe and uncomplicated malaria. Plasmodium falciparum has developed resistance to anti-malarial agents, such as chloroquine in the past and there are reports of the growing resistance of $P$. falciparum to artemisinin derivatives in South-east Asia [3]. An anecdotal study in six West-African countries, including Ghana showed increased failure rates $(10 \%)$ in malaria treatment with artemisinin-based combination therapy [4]. Some malaria vaccines (Plasmodium falciparum sporozoite vaccine (PfSPZ), Chemoprophylaxis vaccination (CVac), Genetically-attenuated parasite vaccine (GAP), RTS,S/AS01) are at various stages of development, but a clinically approved malaria vaccine is not available, therefore [5] making the search for newer, more effective anti-malarial agent still relevant.

Drug combination therapies (DCTs) are pertinent to the optimum control of malaria in developing countries [6] because they provide improved efficacy and might also give synergistic activity. Due to the rapid spread of drug resistance among parasites worldwide, the initial use of single drugs as monotherapies has given way in the last decades to combination therapies of two or more drugs especially the use of agents with different modes of action to improve efficacy and reduce resistance $[7,8]$. Drug combinations also enhance the probability that one agent can be at least clinically active in the case of parasite resistance to the drug. For example, in East Africa, malaria parasites are resistant to both amodiaquine and sulfadoxine-pyrimethamine (SP), but the combination of these two agents still gives an excellent anti-malarial efficacy $[9-11]$.

Natural products are essential in the drug discovery process, and there is no exception in anti-malarial agents. Medicinal plant extracts have been a source for anti-malarial drug discovery for long, and their treatment for malaria has been successful [12]. About 160 plant families have been established to have antimalarial properties. From these families, more than 1200 species have been documented to have antimalarial properties [1], including Xylopia aethiopica which is used to treat malaria by Ghanaian herbal practitioners [13].

Xylopic acid, a kaurene diterpene, is the major constituent of the fruits of Xylopia aethiopica and has been reported to possess anti-malarial properties in Plasmodium berghei-infected ICR mice. Furthermore, it significantly reduced the lipopolysaccharide-(LPS) induced fever in Sprague-Dawley rats [13]. Thus, xylopic acid possesses prophylactic and curative anti-malarial effects along with antipyretic and analgesic properties, making it a promising anti-malarial agent. Artesunate, amodiaquine, and xylopic acid have all been shown to be effective in combination therapies as demonstrated by Ameyaw et al. [14] on the synergistic effect of xylopic acid in combination with cryptolepine in clearing malaria parasites in a malaria experimental model. Similarly, the anti-malarial activity of amodiaquine and artesunate was enhanced when combined with lopinavir/ritonavir [15]. In the present study, we tested the efficacy of xylopic acid/amodiaquine and xylopic acid/ artesunate combination therapy in mice infected with P. berghei.

\section{Methods}

\section{Xylopic acid extraction}

Xylopic acid was extracted from Xylopia aethiopica as previously described [16-18]. Fresh unripe fruits of $X$. aethiopica purchased from the Ho Central Market in Ghana were shade-dried and pulverized with a hammer mill. For every $100 \mathrm{~g}$ of plant material, $300 \mathrm{ml}$ of petroleum ether was used as a solvent for maceration. The mixture of $X$. aethiopica and petroleum ether was left to stand for 3 days with continuous shaking every $24 \mathrm{~h}$. Whatman filter paper was used to filter the mixture and left to stand overnight under dark conditions. The filtrate was then concentrated with a Rotary evaporator (Heidolph Labo Rota, 4002) at 120 revolutions per minute and $40-55^{\circ} \mathrm{C}$. The concentrate was left was to stand for $72 \mathrm{~h}$ and 3 drops of ethyl acetate added to facilitate the crystallization of crude xylopic acid crystals. Crude xylopic acid was washed several times with petroleum ether and dissolved in absolute ethanol for purification by recrystallization. The purity of the xylopic acid was assessed by thin-layer chromatography using petroleum ether and ethyl acetate (9:1) as the solvent system. Pure xylopic acid was used as a reference and both compounds gave $\mathrm{Rf}$ of 0.53 . 


\section{Experimental animals}

Six to ten weeks-old female ICR mice purchased from the Centre for Medicinal Plant Research, AkuapimMampong, Ghana, were used for the study. They were housed in stainless steel cages $\left(16.5 \times 11.0 \times 13.5 \mathrm{~cm}^{3}\right)$ with beddings made from softwood shavings. The animals were kept under appropriate laboratory conditions and fed with a normal commercial pellet diet purchased from Agricare, (Kumasi, Ghana) and water ad libitum. The cages were kept in the Department of Biomedical Sciences animal holding facility, University of Cape Coast, and the wood shavings were replaced every 3 days and disinfected with $70 \%$ alcohol. The facility had a $12 / 12 \mathrm{~h}$ light/dark cycles and a mean temperature of $21^{\circ} \mathrm{C}$.

\section{Drugs, chemicals, and reagents}

Artemether/lumefantrine combined tablets (20/120 mg), artesunate, and amodiaquine were acquired from Novartis Pharma AG Basel, Switzerland. Hydrochloric acid, Giemsa stain, absolute methanol, chloroform, petroleum ether, ammonium hydroxide, 96\% ethanol, liquid paraffin, Tween 20, and ammonium chloride were also purchased from Sigma Aldrich. St Louis, MO, USA.

\section{Plasmodium berghei ANKA parasite acquisition and inoculation}

A chloroquine-sensitive strain of rodent malaria parasite Plasmodium berghei (strain ANKA) was acquired from Noguchi Memorial Institute for Medical Research (NMIMR), University of Ghana and by a continuous passage in mice intraperitoneally every 6 days [19]. Once high parasitaemia (30-40\%) was established in a donor mouse, it was sedated under chloroform, following Hoff's technique [20]. Blood was collected by cardiac puncture and transferred into EDTA tubes, capped, and topped with Phosphate Buffered Saline (PBS). The mixture containing blood, EDTA, and PBS were washed three times by centrifuging with a haematocrit centrifuge, at $15,000 \mathrm{rpm}$ for $6-7 \mathrm{~min}$ to obtain pellets. Total inoculum concentration of $17.4 \times 10^{7} \mathrm{P}$. berghei parasitized erythrocytes were prepared and each mouse was inoculated with $0.20 \mathrm{ml}$ of PBS containing $1.2 \times 10^{6}$ parasitized red blood cells.

\section{Bodyweight measurement}

Mice body weights were measured on days 0 and day 7 post-infection following a procedure described by Dikasso and colleagues [21] using a top pan balance (Toledo ${ }^{\circledR}$ Metler, Japan).

\section{Anti-malarial activity}

In vivo anti-plasmodial assay of xylopic acid, artesunate, and amodiaquine monotherapies

To confirm the reported anti-malarial properties of xylopic acid (XA), artesunate (ART), and amodiaquine $(\mathrm{AQ})$, and also determine their $\mathrm{ED}_{50}$ values for the isobolographic analysis, the anti-plasmodial activity of each compound was assessed. After infection, mice were assigned to 18 groups $(n=5)$. Mice in all groups were inoculated with $P$. berghei except Group 18 mice which served as naïve control. Seventy-two hours post-inoculation (day 3), all groups of animals were treated once daily by oral administration with a gastric gavage with either xylopic acid (3, 10, 30, 100, $\left.150 \mathrm{mg} \mathrm{kg}^{-1}\right)$, artesunate $\left(1,2,4,8,16 \mathrm{mg} \mathrm{kg}^{-1}\right)$, amodiaquine $(1.25,2.5,5,10$, $\left.20 \mathrm{mg} \mathrm{kg}^{-1}\right)$, artemether/lumefantrine (1.14/6.9 $\left.\mathrm{mg} \mathrm{kg}^{-1}\right)$, or vehicle, $10 \mathrm{ml} \mathrm{kg}^{-1}$ (naïve and sham control). The $\mathrm{ED}_{50}$ values obtained as fitted midpoints of XA, ART and AQ were determined by iterative curve fitting of log-dose responses of XA, ART, and AQ. Mice were observed at $12 \mathrm{~h}$ intervals for death and the median survival and hazard ratio over a 30-day period was computed.

In vivo isobolographic assessment of xylopic acid-artesunate co-administration on $P$. berghei-induced malaria

To assess the antiplasmodial property of xylopic acidartesunate (XA/ART) co-administration on established $P$. berghei infection, 6 to 10 weeks female ICR mice were each inoculated with $1.2 \times 10^{6}$ in $0.20 \mathrm{ml} \mathrm{PBS}$ and assigned to 8 groups $(\mathrm{n}=5)$. On day 3, each group received either fixed ratio (1:1) of the $\mathrm{ED}_{50 \mathrm{~s}}$ of XA and ART $\left(9+1.6 \mathrm{mg} \mathrm{kg}^{-1}\right)$ or combinations of fractions of the respective $E D_{50}$ values: $\mathrm{ED}_{50}(\mathrm{XA} / \mathrm{ART}) / 2, \quad\left(4.5+0.8 \mathrm{mg} \mathrm{kg}^{-1}\right), \quad \mathrm{ED}_{50}$ $(\mathrm{XA} / \mathrm{ART}) / 4 \quad\left(2.25+0.4 \quad \mathrm{mg} \quad \mathrm{kg}^{-1}\right), \quad \mathrm{ED}_{50} \quad(\mathrm{XA} /$ ART)/8, $\quad\left(1.13+0.2 \mathrm{mg} \quad \mathrm{kg}^{-1}\right), \quad \mathrm{ED}_{50} \quad(\mathrm{XA} / \mathrm{ART}) / 16$ $\left(0.6+0.1 \mathrm{mg} \mathrm{kg}^{-1}\right.$. Positive control (AL) and negative control (sham) mice received 1.14/6.9 $\mathrm{mg} \mathrm{kg}^{-1} \mathrm{AL}$ and $10 \mathrm{ml} \mathrm{kg}^{-1}$ vehicle, respectively.

\section{In vivo isobolographic assessment of xylopic acid-amodiaquine co-administration on P. berghei-induced malaria}

To assess the anti-plasmodial property of xylopic acidamodiaquine (XA/AQ co-administration, on established P. berghei infection, 6 to 10 weeks female ICR mice were each inoculated with $1.2 \times 10^{6}$ in $0.2 \mathrm{ml}$ PBS and assigned to 8 groups $(n=5)$. Seventy-two hours later, each group received fixed ratio $(1: 1)$ or combinations of fractions of the respective $\mathrm{ED}_{50}$ values of $\left(9+3.1 \mathrm{mg} \mathrm{kg}^{-1}\right)$, $\left(4.5+1.6 \mathrm{mg} \quad \mathrm{kg}^{-1}\right), \quad\left(2.25+0.8 \quad \mathrm{mg} \quad \mathrm{kg}^{-1}\right)$, $\left(1.125+0.4 \mathrm{mg} \mathrm{kg}^{-1}\right),\left(0.6+0.2 \mathrm{mg} \mathrm{kg}^{-1}\right), \mathrm{ED}_{50}(\mathrm{XA} / \mathrm{AQ})$, 
$\mathrm{ED}_{50}(\mathrm{XA} / \mathrm{AQ}) / 2, \mathrm{ED}_{50}(\mathrm{XA} / \mathrm{AQ}) / 4, \mathrm{ED}_{50}(\mathrm{XA} / \mathrm{AQ}) / 8$, and $\mathrm{ED}_{50}(\mathrm{XA} / \mathrm{AQ}) / 16$, respectively. Positive control (AL) and negative control (sham) mice received 1.14/6.9 $\mathrm{mg} \mathrm{kg}^{-1}$ AL and $10 \mathrm{ml} \mathrm{kg}^{-1}$ vehicle, respectively.

\section{Percentage chemo-suppression and parasitemia evaluation}

Parasitaemia was tracked using thin blood smears made daily for 5 days by collecting three drops of blood from the tail of each mouse, fixed in absolute methanol, and stained in 10\% Giemsa for $10 \mathrm{~min}$ to determine parasitaemia. The slides were microscopically examined at $100 \times$ magnification. Parasitaemia was checked by counting infected red blood cells in hundred fields, divided by the total red blood cells in the hundred fields, and then multiplied by hundred and percentage parasitaemia calculated as follows:
SEMs were calculated from these variances and fixed according to the drug's ratio in the combination. If the effect of a drug combination was statistically different $\left(E_{50}\right.$ significantly lower) and higher than the theoretically calculated equieffect of a drug combination in the same proportion, it has a supra-additive or synergistic effect.

\section{Results}

In vivo anti-malarial assay of xylopic acid, artesunate, and amodiaquine monotherapies

Effects of $X A, A R T$, and $A Q$ monotherapy on body weight

Amodiaquine and artesunate treatment groups significantly reduced weight loss in mice infected with $P$. berghei $(\mathrm{p}=0.001)$. In XA-treated groups, loss in body weight was not statistically significant. High doses of artesunate $(8 \mathrm{mg} /$

$$
\% \text { Parasitaemia }=\frac{\text { Number of Plasmodium berghei }- \text { infected erythrocytes }}{\text { Total number of erythrocytes }} \times 100 .
$$

Chemosupression or percentage inhibition of parasitaemia was computed by employing the following formula:

$$
\% \text { inhibition }=\frac{(\text { Mean parasitaemia of negative control })-(\text { Mean parasitaemia of test drug })}{\text { Mean parasitaemia of negative control }} \times 100 \text {. }
$$

\section{Data analysis}

All statistical analyses were computed with the windows version of GraphPad Prism 7.0 (GraphPad Software, San Diego, CA, USA). Data were considered significant at $p<0.05$ and were presented as the mean \pm SEM. Tukey's honest significant difference (HSD) test was used as a post hoc test. Two isobolograms which consisted of the $\mathrm{ED}_{50}$ of XA on the ordinate and $\mathrm{ED}_{50}$ of ART or AQ on the abscissa connected with a line of additivity were constructed. The $\mathrm{ED}_{50}$ of each drug was determined by linear regression analysis of the log dose-response curve (and a T-test was used for the comparison to a theoretical additive $\mathrm{ED}_{50}$ i.e. $\left.Z_{\text {add }}\right) . Z_{\text {add }}$ was computed with the following formulae:

$$
Z_{\text {add }}=(f) E D 50 \text { of } A R T+(1-f) E D 50 \text { of } X A
$$

and

$$
Z_{\text {add }}=(f) E D 50 \text { of } A Q+(1-f) E D 50 \text { of } X A,
$$

$\mathrm{kg})$ and amodiaquine $(10 \mathrm{mg} / \mathrm{kg})$ showed an increase in body weight similar to the naïve and AL groups (Fig. 1).

\section{Effects of $X A, A R T$, and $A Q$ monotherapy on post-treatment} survival

Artemether/lumefantrine-treated animals had 26 median survival days with a hazard ratio of 0.20 in the 30 days survival test (Fig. 2), representing the highest survival days and lowest hazard ratio in the treatment groups. Middle doses of XA (30 mg/kg), AQ (10 mg/kg), and high doses of ARTtreated groups also significantly increased survival days in the 30 days survival test $(\mathrm{p}<0.05)$ (Table 1, Fig. 2).

\section{Anti-plasmodial effects of XA, ART, and AQ monotherapy}

The anti-malarial activities of XA, ART, and AQ were individually evaluated in $P$. berghei-infected mice. Infection was established on day 3 ( $72 \mathrm{~h}$ post-infection) for all groups. $\mathrm{ED}_{50} \mathrm{~s}$ for xylopic acid, artesunate, and amodiaquine were $9.0 \pm 3.2,1.61 \pm 0.6$, and $3.1 \pm 0.8 \mathrm{mg} / \mathrm{kg}$. By these results, the artesunate was 1.9 times more potent than amodiaquine, and amodiaquine was 2.9 times more potent than xylopic acid (Fig. 3).

where $\mathrm{f}$ is the fraction of each component in the mixture/ combination while the Var (variance) of $\mathrm{Z}_{\text {add }}$ was computed as follows:

$$
\text { Variance of } Z_{\text {add }}=f 2(\operatorname{VarED50} \text { of CYP })+(1-f) 2 \operatorname{VarED50} \text { of XA. }
$$



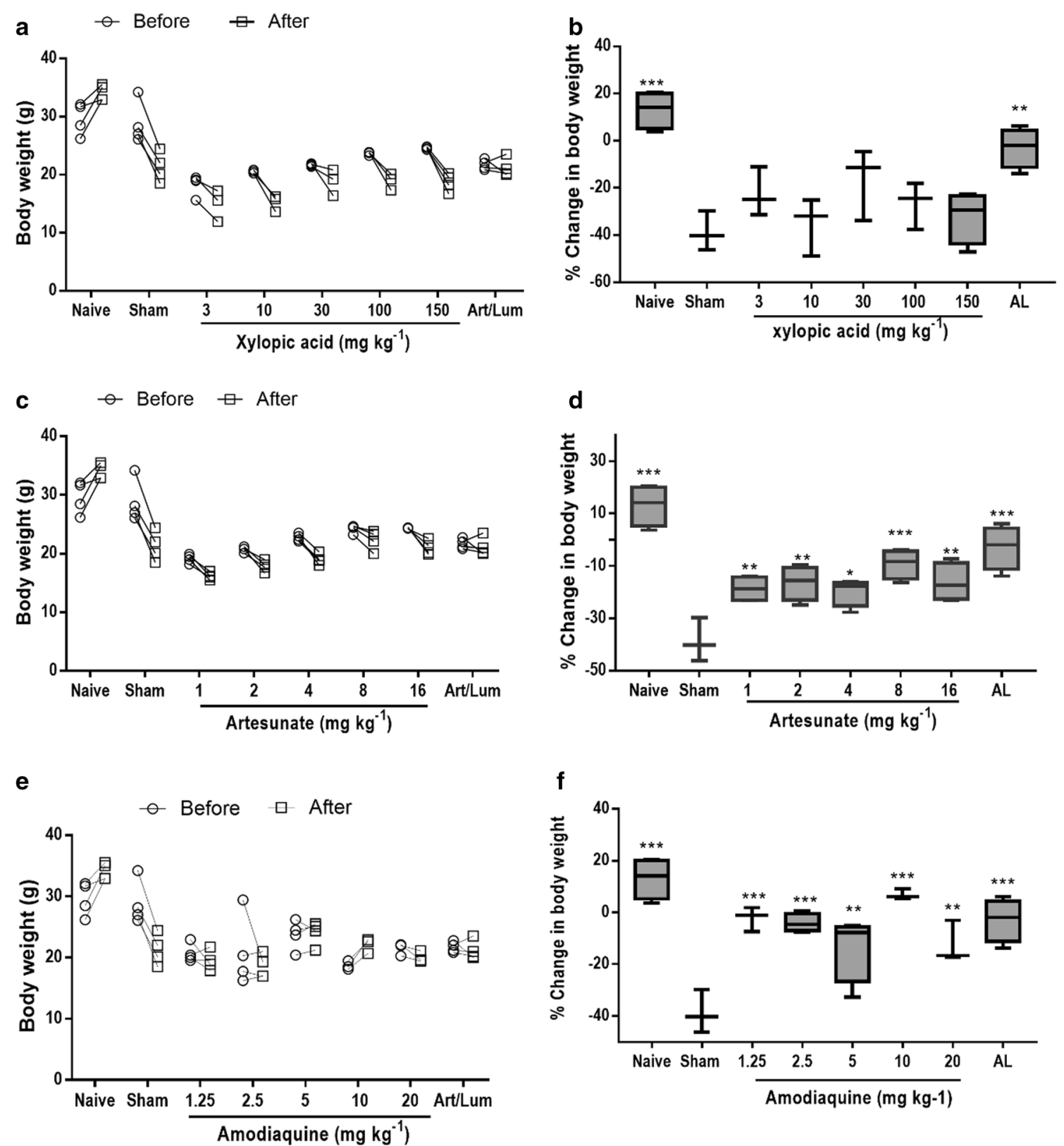

Fig. 1 Bodyweight before infection and after treatment (left panel) and percentage change in body weight (right panel) for a, b xylopic acid, c, d artesunate, and $\mathbf{e}$, $\mathbf{f}$ amodiaquine treated groups. Data are presented as mean $\pm \operatorname{SEM}(n=5), p<0.05$

In vivo assessment of xylopic acid-artesunate and xylopic acid-amodiaquine co-administration of $\mathrm{PbA}$-induced malaria Effects of $X A+A R T$ and $X A+A Q$ combination on weight loss $\mathrm{AL}, \quad 5.3 \mathrm{mg} / \mathrm{kg} \mathrm{XA}+\mathrm{ART}, 10.6 \mathrm{mg} / \mathrm{kg} \mathrm{XA}+\mathrm{ART}$, $6.1 \mathrm{mg} / \mathrm{kg} \mathrm{XA}+\mathrm{AQ}$, and 12.1 XA + AQ treated groups significantly reduced loss in body weight compared to the sham-treated group ( $\mathrm{p}<0.05)$ (Fig. 4).

\section{Effects of XA + ART and XA+AQ combination} on parasetemia and chemosuppression

Percentage chemosupression for the highest combination doses of both XA/ART (Table 2) and XA/ AQ (Table 3) suppressed parasite growth similar to artemether/lumefantrine (Fig. 5). The $\mathrm{ED}_{50} \mathrm{~s}$ for xylopic 


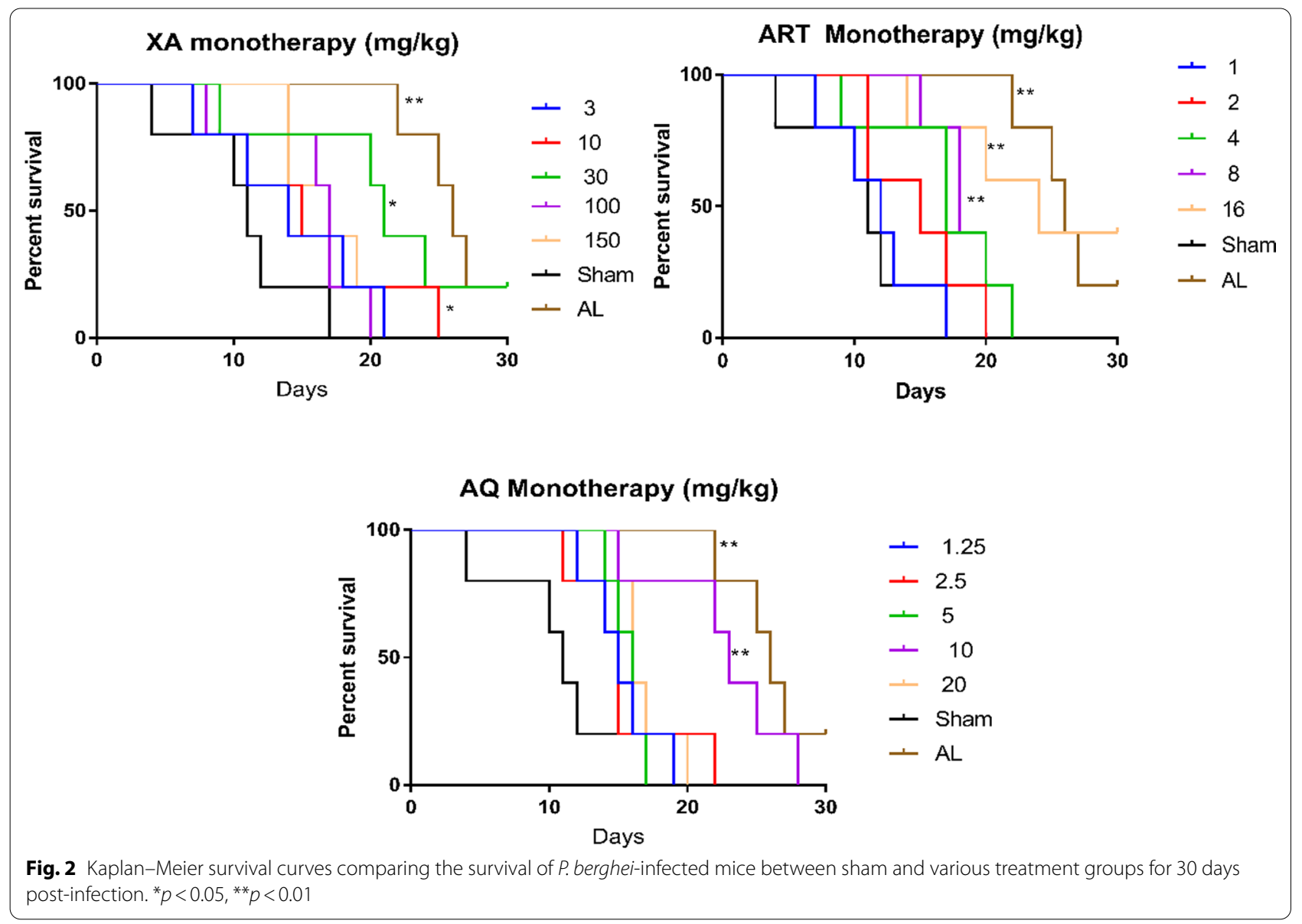

acid-artesunate and xylopic acid-amodiaquine were $1.98 \pm 0.33$ and $1.69 \pm 0.83$, respectively (Fig. 6).

\section{Survival analysis for combination therapy}

The XA/AQ combination doses significantly delayed death in in $P$. berghei-infected mice in a 30-day survival test, similar to the AL treated group. Likewise, the high doses of the XA/ART combination increased the survival days of the P. berghei-infected mice (Table 4, Fig. 7).

\section{Isobolographic analysis of antiplasmodial effects of $X A$ and $A R T$, and $X A$ and $A Q$ co-administration}

Xylopic acid-artesunate co-administration had a theoretical $\mathrm{ED}_{50}\left(\mathrm{Z}_{\text {add }}\right)$ of $5.3 \pm 2.61$, whereas the experimental $\mathrm{ED}_{50}\left(\mathrm{Z}_{\text {exp }}\right)$ was obtained as $1.98 \pm 0.25$ (Table 5). Also, the co-administration of xylopic acid and amodiaquine had a theoretical $\mathrm{ED}_{50}$ value of $6.05 \pm 2.0$; however, the experimental $\mathrm{ED}_{50}$ was $1.69 \pm 0.42$. Thus, the $\mathrm{Z}_{\mathrm{exp}}$ for both combinations lies significantly below the line of additivity since the interaction index was calculated to be 0.37 and 0.28 for xylopic acid-artesunate and xylopic acid-amodiaquine (Fig. 8).

co-administration,

respectively

\section{Discussion}

Plasmodium falciparum has developed resistance to antiplasmodial agents over the years and has been reported to acquire resistance to currently used anti-malarial drugs [22]. Growing evidence of the resistance of P. falciparum to even artemisinin derivatives calls for the urgent need for more efficient and safer anti-malarials and nature remains a key source for such novel anti-malarial agents [23]. Combination therapy is a good strategy in antimicrobial chemotherapy because it enhances the probability of sustained efficacy in the advent of parasite resistance to one agent [24]. The combination also helps in preventing the development of resistance due to their multiple mechanisms of action making evasion by the parasite significantly difficult. Combination therapy also improves efficacy when the agents act synergistically [9]. Against this background, this study examined the effectiveness of combining each of two established anti-malarial agents, 
Table 1 30-day survival analysis of Plasmodium bergheiinfected mice after treatment with either xylopic acid, artesunate, amodiaquine, or artemether/lumefantrine

\begin{tabular}{|c|c|c|c|}
\hline $\begin{array}{l}\text { Treatment (mg/ } \\
\text { kg) }\end{array}$ & $\begin{array}{l}\text { Median survival } \\
\text { (days) }\end{array}$ & $\begin{array}{l}\text { Hazard ratio (log- } \\
\text { rank) }\end{array}$ & $p$-value \\
\hline Naïve & 30 & - & - \\
\hline Sham & 11 & & \\
\hline \multicolumn{4}{|l|}{$X A$} \\
\hline 3 & 14 & 0.49 & 0.2017 \\
\hline 10 & 15 & 0.49 & 0.2017 \\
\hline 30 & 21 & 0.15 & $0.0269^{*}$ \\
\hline 100 & 17 & 0.46 & 0.1401 \\
\hline 150 & 17 & 0.32 & $0.0272^{*}$ \\
\hline \multicolumn{4}{|l|}{ ART } \\
\hline 1 & 12 & 0.84 & 0.7501 \\
\hline 2 & 15 & 0.51 & 0.2088 \\
\hline 4 & 17 & 0.39 & 0.0689 \\
\hline 8 & 18 & 0.25 & $0.0064^{* *}$ \\
\hline 16 & 24 & 0.20 & $0.0064^{* *}$ \\
\hline \multicolumn{4}{|l|}{$\mathrm{AQ}$} \\
\hline 1.25 & 15 & 0.47 & 0.1843 \\
\hline 2.5 & 15 & 0.48 & 0.1842 \\
\hline 5 & 16 & 0.53 & 0.2097 \\
\hline 10 & 23 & 0.25 & $0.0064^{* *}$ \\
\hline 20 & 16 & 0.40 & 0.0812 \\
\hline $\mathrm{AL}$ & 26 & 0.20 & $0.0018^{* *}$ \\
\hline
\end{tabular}

$(\mathrm{n}=5),{ }^{*}$ means $\mathrm{p}<0.05$

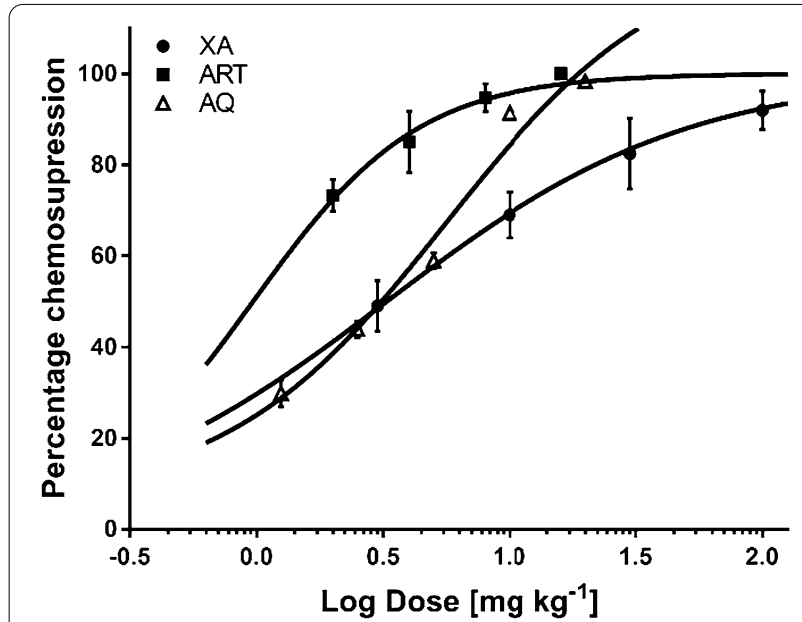

Fig. 3 Log dose-response curves of percentage chemosupression in P. berghei-infected mice administered daily with xylopic acid, artesunate, or amodiaquine over 5 days. Data are presented as mean \pm SEM $(n=5)$ artesunate and amodiaquine, with an investigational antiplasmodial agent, xylopic acid.

Xylopic acid, extracted from the unripe fruits of Xylopia aethiopica has been examined previously to have antiplasmodial, anti-inflammatory, antipyretic [13], and analgesic [17] properties. Also, it has been recently reported to act synergistically when combined with other plant-derived antiplasmodial compounds such as cryptolepine [14]. These properties are crucial in the management of malaria symptomatology, making xylopic acid a potential anti-malarial agent for further drug development and a good candidate for combination therapy in anti-malarial chemotherapy.

Combining xylopic acid with either artesunate or amodiaquine showed a remarkable suppression in parasite growth similar to the artemether/lumefantrine. Although, monotherapy of XA, ART, and AQ also suppressed parasite growth compared to artemether/lumefantrine it occurred at higher doses. An isobolographic analysis was employed to determine the enhanced or improved potency and efficacy of xylopic acid-artesunate, and xylopic acid-amodiaquine combination therapies. An isobolographic analysis gives a central basis for evaluating whether a biological response induced by a mixture of agents is smaller, equal, or greater on the concept of dose additivity and the basis of the components or agents' activities [25]. The co-administration of xylopic acid and artesunate showed significant antiplasmodial activity in comparison to the sham-treated mice. The isobologram showed that when xylopic acid and artesunate are administered together, the $\mathrm{Z}_{\text {exp }}$ was significantly below the line of additivity ("additive" isobole) and the $Z_{\text {add }}$, which means the two drugs have a synergistic antiplasmodial effect. The interaction index of 0.37 , which is significantly less than 1 , confirms a synergistic relationship [26] and a supra-additive effect between artesunate and xylopic acid.

Compared to a recent study by Ameyaw et al. [14], combining xylopic acid and artesunate gave a higher supra-additivity and synergistic interaction than xylopic acid and cryptolepine combination, probably, due to the high synergistic property of artesunate [27-29]. Nevertheless, xylopic acid-cryptolepine co-administration showed a higher parasite clearance rate of $78 \%$ for the higher dose combination compared to the $75 \%$ for the higher dose combination of xylopic acid and artesunate. Another study that examined the chemotherapeutic interactions between anti-malarial drugs and 

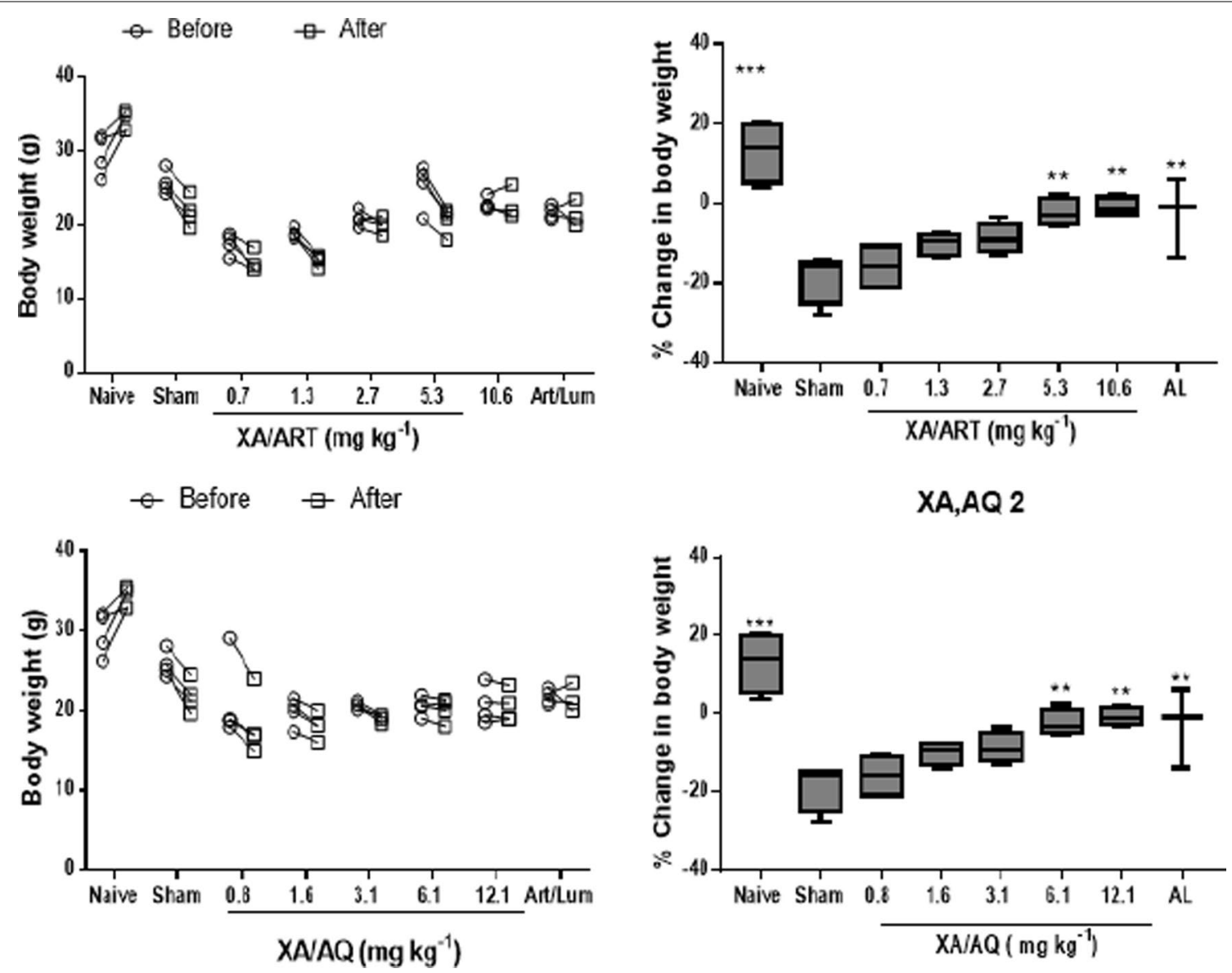

Fig. 4 Bodyweight before infection and after treatment and percentage change in body weight for $\mathbf{a}, \mathbf{b}$ xylopic acid-artesunate, and $\mathbf{c}$, $\mathbf{d}$ xylopic acid-amodiaquine combination-treated groups. Data are represented as mean $\pm \operatorname{SEM}(n=5), p<0.05$

Table 2 Percentage parasitemia and chemosupression of mice treated with different doses of xylopic acid + artesunate combination for 5 days

\begin{tabular}{|c|c|c|}
\hline Treatment $\left(\mathrm{ED}_{50} \mathrm{mg} / \mathrm{kg}\right)$ & Dose (mg/kg) & $\begin{array}{l}\% \text { Chem supp } \\
\text { Day } 6\end{array}$ \\
\hline Sham & $0.50 \mathrm{ml}$ & - \\
\hline (XA/ART)16 & 0.6:0.1 & $21.5 \pm 0.6$ \\
\hline$(\mathrm{XA} / \mathrm{ART}) / 8$ & $1.13: 0.2$ & $24.1 \pm 0.5$ \\
\hline$(\mathrm{XA} / \mathrm{ART}) / 4$ & 2.25:0.4 & $52.2 \pm 0.8$ \\
\hline$(\mathrm{XA} / \mathrm{ART}) / 2$ & $4.5: 0.8$ & $66.8 \pm 0.1$ \\
\hline (XA/ART) 10.6 & $9.0: 1.61$ & $75.7 \pm 1.2$ \\
\hline AL 1.14 & - & $84.6 \pm 1.6$ \\
\hline
\end{tabular}

Data are presented as mean \pm SEM, $(n=5)$

antiretroviral drugs observed an increase in antimalaria activity when ART was combined with lopinavir/ritonavir (LR) on day 5 post-infection in mice infected with P. berghei [15] confirming the synergistic interaction of artesunate with other potent drugs.
Table 3 Percentage parasitemia and chemosupression of mice treated with different doses of xylopic acid + amodiaquine combination for 5 days

\begin{tabular}{lll}
\hline Treatment $\left(\mathrm{ED}_{\mathbf{5 0}} \mathbf{~ m g} / \mathbf{k g}\right)$ & Dose $\mathbf{( m g / k g )}$ & $\begin{array}{l}\text { \% Chem sup } \\
\text { Day } \mathbf{6}\end{array}$ \\
\hline Sham & $0.50 \mathrm{ml}$ & - \\
$(\mathrm{XA} / \mathrm{AQ}) / 16$ & $0.6: 0.2$ & $41.2 \pm 1.3$ \\
$(\mathrm{XA} / \mathrm{AQ}) / 8$ & $1.125: 0.4$ & $43.9 \pm 1.9$ \\
$(\mathrm{XA} / \mathrm{AQ}) / 4$ & $2.25: 0.8$ & $56.4 \pm 0.8$ \\
$(\mathrm{XA} / \mathrm{AQ}) / 2$ & $4.5: 1.6$ & $68.4 \pm 1.3$ \\
$(\mathrm{XA} / \mathrm{AQ}) 12.1$ & $9.0: 3.1$ & $79.8 \pm 0.9$ \\
$\mathrm{AL} \mathrm{1.14}$ & - & $88.3 \pm 0.4$ \\
\hline
\end{tabular}

Data are presented as mean \pm SEM, $(n=5)$

The observed increased antiplasmodial activity of the XA/ART combination could also be attributed to the two drugs interacting with several targets in the parasite. XA inhibits plasmodium dehydrogenase [30], an enzyme that catalyzes the reduction of pyruvate 

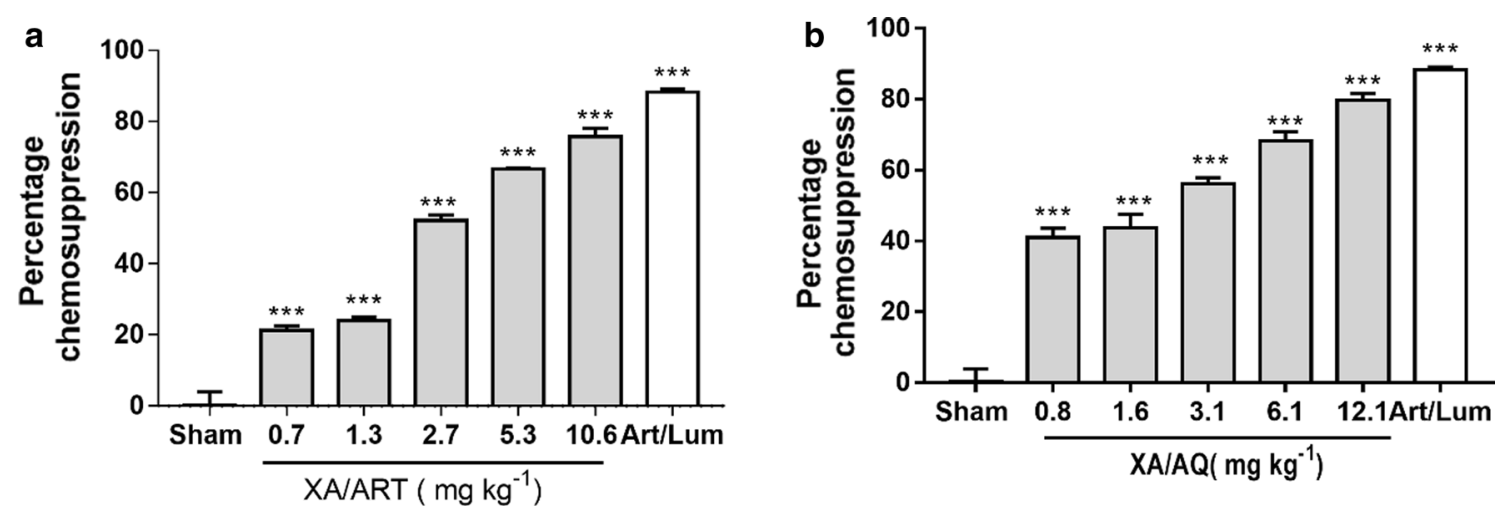

Fig. 5 Percentage chemosupression for $\mathbf{a}$ xylopic acid-artesunate and $\mathbf{b}$ xylopic acid-amodiaquine treated P. berghei-infected mice. Data are presented as mean \pm SEM, $(n=5), p<0.05$

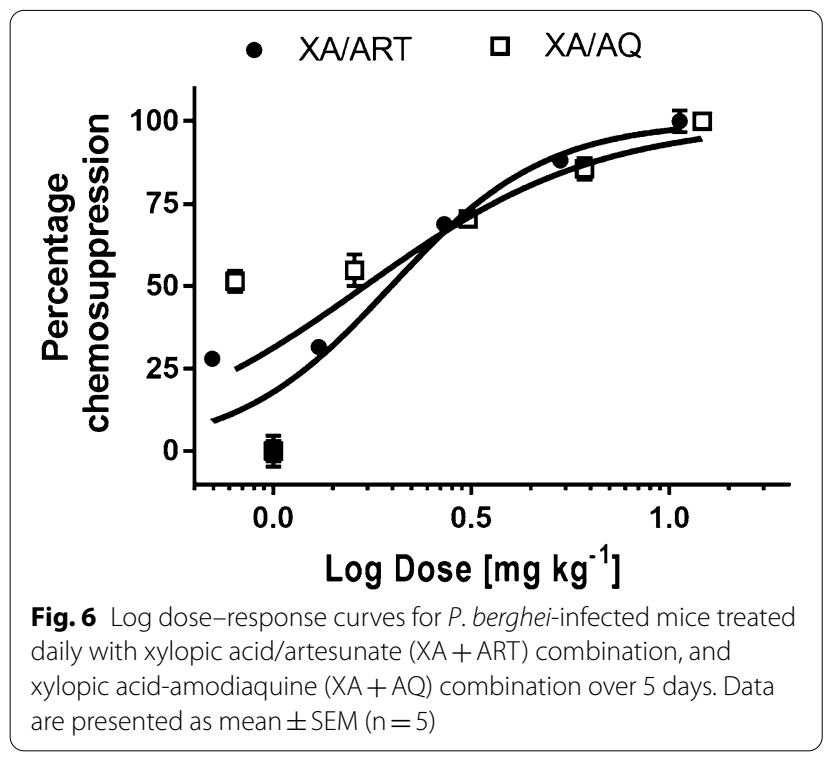

to lactate, crucial for energy production, whilst artemisinin derivatives are believed to undergo reductive activation of the peroxide group in the presence of ferrous ion which is released upon haemoglobin digestion within the food vacuole of the parasite [14, 31]. This forms a carbon-centered radical which alkylates vital parasite proteins such as heme and membrane-associated parasite proteins [32,33]. Thus, the inhibition of different metabolic steps in Plasmodium haemoglobin digestion of parasite glycolysis might contribute to the enhanced antiplasmodial activity of ART and XA.

Furthermore, the anti-inflammatory properties of xylopic acid may have contributed to the limiting survival of the parasite. Osafo and colleagues recently reported the anti-inflammatory properties of xylopic acid against various phlogistic agents (bradykinin,
Table 4 Thirty-day survival analysis of Plasmodium berghei-infected mice after treatment with xylopic acid and amodiaquine, and xylopic acid and artesunate

\begin{tabular}{llll}
\hline $\begin{array}{l}\text { Treatment (mg/ } \\
\mathbf{k g})\end{array}$ & $\begin{array}{l}\text { Median survival } \\
\text { (days) }\end{array}$ & $\begin{array}{l}\text { Hazard ratio (log- } \\
\text { rank) }\end{array}$ & $\boldsymbol{p}$-value \\
\hline Sham & 10.5 & & \\
(XA/ART) & & & \\
0.7 & 10 & 0.52 & 0.1766 \\
1.3 & 12 & 0.59 & 0.2941 \\
2.7 & 16 & 0.35 & $0.0374^{*}$ \\
5.3 & 16 & 0.35 & $0.0374^{*}$ \\
10.6 & 19 & 0.23 & $0.0021^{* *}$ \\
(XA/AQ) & & & \\
0.8 & 13 & 0.34 & $0.0297^{*}$ \\
1.6 & 15 & 0.14 & $0.0297^{*}$ \\
3.1 & 15 & 0.33 & $0.0224^{*}$ \\
6.1 & 20 & 0.29 & $0.0112^{*}$ \\
12.1 & 24 & 0.23 & $0.0021^{* *}$ \\
AL & 27 & 0.21 & $0.0021^{* *}$ \\
\hline
\end{tabular}

$(\mathrm{n}=5),{ }^{*}$ means $\mathrm{p}<0.05$

serotonin, carrageenan, histamine, and prostaglandin $\mathrm{E}_{2}$ ). XA inhibited albumin denaturation, and also maximal edema, and average paw thickness induced by the phlogistic agents for both prophylactic and therapeutic studies. It also inhibited the arachidonic acid pathway $[34,35]$. Inflammation plays a key role in the pathogenesis of malaria. Following $P$. berghei infection, splenic dendritic cells, $\mathrm{CD} 8 \alpha^{+}$and $\mathrm{Clec} 9 \mathrm{~A}^{+}$phagocytose, and cross-present parasite antigens which lead to the priming of parasite-specific $\mathrm{CD} 4^{+}$and $\mathrm{CD}^{+} \mathrm{T}$ cells. Circulating parasitized red blood cells (pRBC) adhere to the endothelium of blood vessels releasing inflammatory ligands such as hemozoin crystals which contain 
XA\& ART Combination therapy $(\mathrm{mg} / \mathrm{kg})$

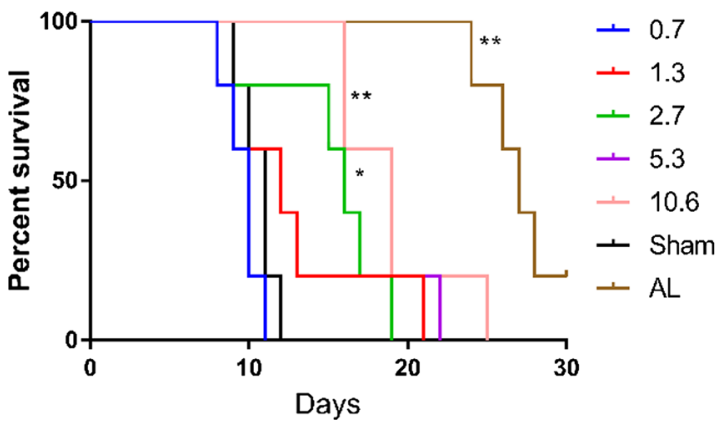

XA \& AQ Combination therapy $(\mathrm{mg} / \mathrm{kg})$

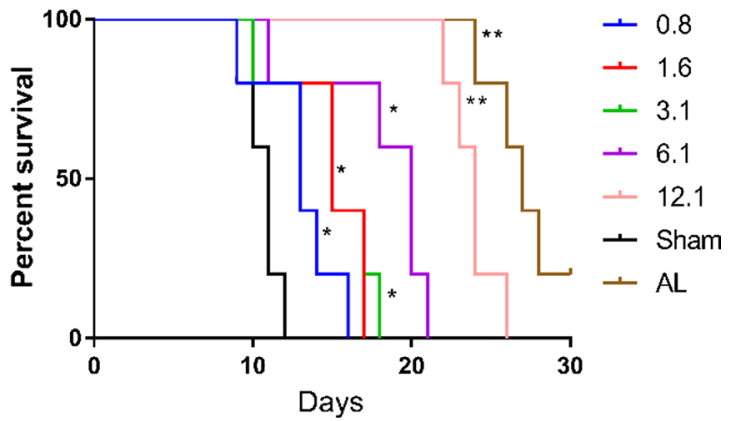

Fig. 7 Kaplan-Meier survival curves comparing the 30 days-post treatment survival of $P$. berghei-infected mice treated with $X A / A R T, X A / A Q$, or $A L$

Table 5 Theoretical $\left(Z_{\text {add }}\right)$, and experimental $\left(Z_{\text {exp }}\right) E_{50}$ of xylopic acid and artesunate, and xylopic acid and amodiaquine co-administration in the anti-malarial assay

\begin{tabular}{llll}
\hline$E_{\mathbf{5 0}} \mathbf{s}(X A / A R T ~ 1: 1)$ & Anti-malarial activity & ED $_{\mathbf{5 0}}$ s $(X A / A Q$ 1:1) & Anti-malarial activity \\
\hline$Z_{\text {add }}(\mathrm{mg} / \mathrm{kg})$ & $5.3 \pm 2.61$ & $Z_{\text {add }}\left(\mathrm{mg} \mathrm{kg}^{-1}\right)$ & $6.05 \pm 2.0$ \\
$Z_{\text {exp }}(\mathrm{mg} / \mathrm{kg})$ & $1.98 \pm 0.25$ & $Z_{\text {exp }}\left(\mathrm{mg} \mathrm{kg}^{-1}\right)$ & $1.69 \pm 0.42$ \\
Interaction index & 0.37 & Interaction index & 0.28 \\
\hline
\end{tabular}

Data are presented as mean \pm SEM
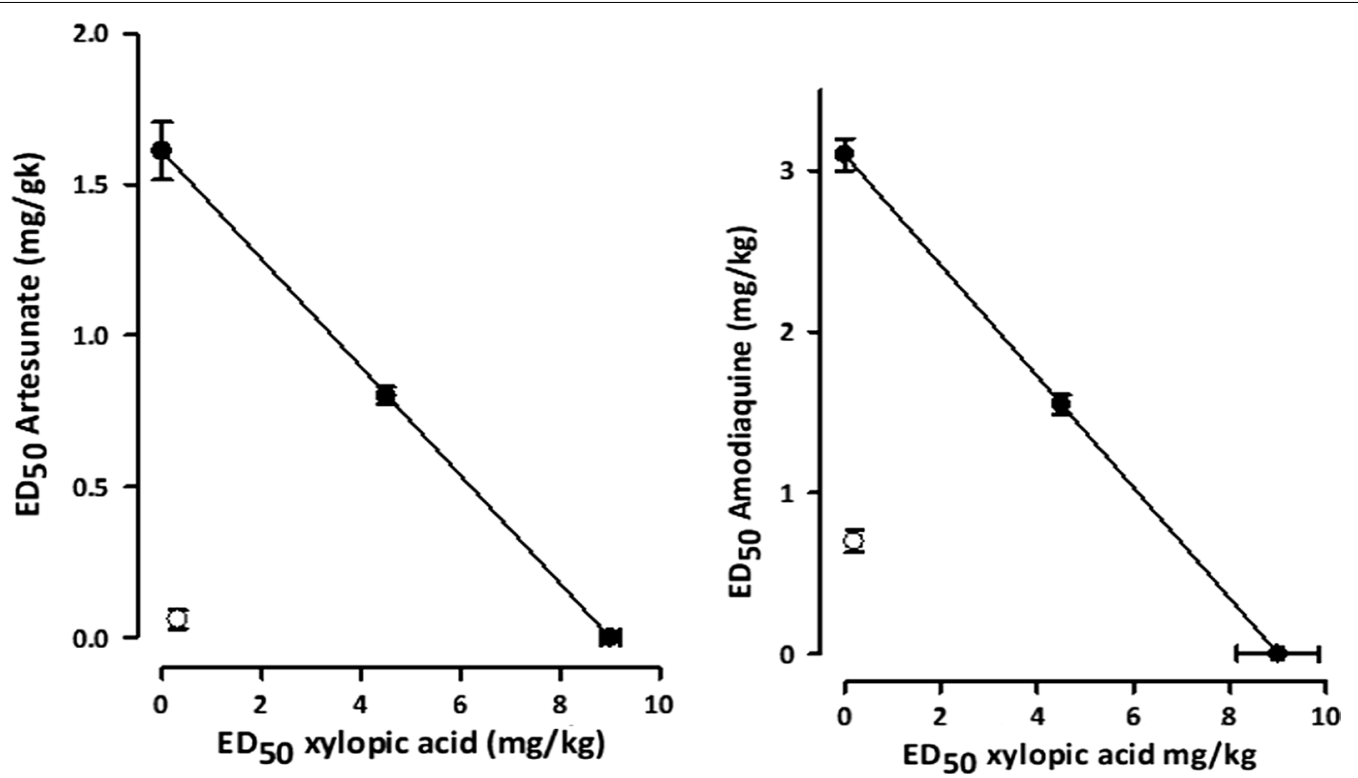

Fig. 8 Isobologram of the co-administration of xylopic acid and artesunate, and xylopic acid and amodiaquine. Filled circles show theoretical $E_{50} \pm S E M$, while open circles show experimental ED $50 \pm$ SEM. The line of additivity connects the ED 50 of xylopic acid on the abscissa to that of artesunate and amodiaquine on the ordinate

parasite DNA. These stimuli are responded to by the release of cytokines and chemokines leading to the upregulation of adhesion molecules (ICAM, VCAM) and receptors (CXCR3) capable of presenting antigens
[36]. When adhesion molecules are upregulated, they aid in the primary rolling and tethering interactions between lymphocytes, granulocytes, and monocytes to endothelial cells at sites of tissue injury. If perturbed 
endothelial cells interact with monocytes along with synergistic action of proinflammatory molecules, they potentially exacerbate tissue factor expression and subsequently activate endothelial cells sustaining coagulation-inflammation cycle [37-40], hence, promoting the "vicious" cycle of coagulation-inflammation of sepsis, which is found to be crucial in malaria pathogenesis. Also, the adherence of parasites to the endothelium with the help of upregulated adhesion molecules following inflammation helps in the survival of parasites. Hence, the acute anti-inflammatory properties might prevent the coagulation-inflammation cycle contributing to the limited growth and survival of mice treated with xylopic acid-amodiaquine, and xylopic acidartesunate combination.

Plasmodium parasites have over the years evolved several biomolecular strategies for escaping immune response to secure parasite survival in the host. One-way parasites achieve immune escape is via the exploitation of host components such as inflammation and platelets that can cause infected red blood cells (iRBCs) and uninfected RBCs to agglutinate promoting the appropriate microenvironment for sequestration [41-43]. The release of a collection of mediators of inflammation may either result in an exacerbated immune response leading to pathology [44]. $\mathrm{CD} 4^{+} \mathrm{T}$-helper cells have been reported to be involved in malaria conferring protection. However, they have also been implicated in immune evasion and malaria pathogenesis [45]. Despite all this, the demonstrated significant anti-inflammatory properties of XA [34, 46] might have prevented the poor outcome of malaria in the XA-ART, XA-AQ treated groups.

A combination of xylopic acid and amodiaquine showed enhanced activity due to their synergistic interaction. Like the XA/ART combination, XA/AQ interaction also showed an interaction index of 0.13 , which is significantly different from [1]. XA/AQ isobologram lay below the line of additivity, confirming the synergistic interaction between the two compounds. The precise molecular mechanisms by which these two agents act is not very clear, but several proteins in the parasite might be a target. AQ metabolite (desethylamodiaquine) is thought to accumulate in parasites food vacuole preventing the conversion of toxic haem produced due to intraerythrocytic parasite digestion of haemoglobin into crystalline haemozoin which is non-toxic to the host but irreversibly toxic to the parasite as a result of the build-up of haem levels [33]. Previous works on anti-malarial combination therapies have shown that, when aspartyl PI is combined with other haemoglobin digestion inhibitors, it acts synergistically [33] but acts antagonistically with vacuole plasmepsin inhibitors [47]. The mechanisms employed by individual drugs of the combination to inhibit metabolic steps in the digestion of haemoglobin may result in the enhanced anti-malarial activity of XA in the presence of $A Q$ and ART shown in this study.

In malaria treatment, like any other infectious disease, it is crucial not only to pay attention to the pathogen but also the reduction of the symptoms of the infection which independently increases the pathogen burden [48]. Among the several general features of malaria infection is the loss of body weight. Weight loss can be attributed to metabolic function disturbance and hypoglycemia caused by malaria parasite infection [49-51]. Hypoglycaemia in malaria patients can also be attributed to the increase in glucose uptake by the febrile host and the parasite. Alternatively, the host's glucose production may be impaired [52]. Thus, an ideal anti-malarial drug is anticipated to prevent the decrease in body weight of mice due to rising parasitaemia, which is crucial for mice survival. $\mathrm{AQ}$ and ART prevented the loss of weight of infected mice significantly $(\mathrm{p}=0.001)$. Although the XA monotherapy experiment did not significantly prevent weight loss, the combination therapy with ART and AQ showed a significant reduction in weight loss in the $10.6 \mathrm{mg} / \mathrm{kg}$ and $12.1 \mathrm{mg} / \mathrm{kg}$ combination doses. This observation correlates with other studies where a combination of xylopic acid and cryptolepine prevented a loss in body weight in mice infected with $P$. berghei $[14,18]$. It is possible that the enhanced antiplasmodial effect of the combination therapy suppressed parasite growth which led to a decrease in glucose intake by the parasite and also restored the animals' appetite as they recovered from the disease.

All the characteristics of an ideal anti-malarial agent should be able to prevent eventual death caused by parasites by suppressing the growth of parasites, thereby reducing the risk of death. An increase in parasite growth causes various symptoms of malaria which eventually leads to the death of the hosts [53]. The hazard ratio is used in drug treatment to describe the relative risk of complication when compared to event rates. In this study, the hazard ratio was measured to describe the outcome of the drug's safety in the malaria treatment in relation to mice survival days. The XA and AQ monotherapy showed a significant increase in the survival days for the middle doses while the high doses showed increased parasite clearance but reduced median survival days and increased hazard ratios. Notwithstanding, the high doses of the ART-treated group showed significant increased median survival days and reduced hazard ratio similar to AL. Surprisingly, in the combination therapy, the XA/ ART treatment groups showed higher parasite clearance compared to $\mathrm{XA} / \mathrm{AQ}$, but their median survival day was only significant in the high doses with a mean hazard ratio of 0.40 , meanwhile, XA and AQ which showed 
significant increased survival days and reduced hazard ratio in only the middle doses during the monotherapy, had a significant increase in survival days for all the combination doses with a mean hazard ratio of 0.27 similar to AL. It is a possibility that the early death of the animals in the XA/ART could have been due to the toxicity of the combination since there was high parasite clearance $[14,54]$. AQ has been consistently reported to be relatively toxic $[55,56]$. Several studies indicate amodiaquine combination therapy could cause fetal death in animals, and indeed, there have been reports of fetal resorption in early pregnancies [57]. The WHO, hence, recommends the avoidance of these drugs in the first trimester, but the problem can still exist if some women fail to recognize their conception at early stages. Notwithstanding, there was increased survival days for the xylopic acidamodiaquine treated group in relation to the xylopic acid-artesunate treated groups, although, it had a lower parasite clearance. Thus, hypothetically, the combination of xylopic acid with $\mathrm{AQ}$ reduced the toxicity of $\mathrm{AQ}$. Median survival for both AL and XA/AQ was statistically significant.

\section{Conclusion}

The findings of this study is heartwarming in the light of the report of growing resistance to current artemisinin [58]. The combination of xylopic acid with either amodiaquine or artesunate seemed to have increased efficacy since lower doses of each of the agents were required to produce a significant therapeutic effect, and also reduced toxicity in the xylopic acid and amodiaquine combination.

\section{Abbreviations}

ACT: Artemisinin-based combination therapy; ART: Artesunate; AQ: Amodiaquine; CPE: Cryptolepine; DCTs: Drug combination therapies; $\mathrm{ED}_{50}$ : Median effective dose; HSD: Honest significant difference; ICR: Institute for cancer research; LPS: Lipopolysaccharide; pRBC: Parasitized red blood cells; SEM: Standard error of mean; SP: Sulfadoxine-pyrimethamine; XA: Xylopic acid; $Z_{\text {add: }}$ Theoretical $\mathrm{ED}_{50} ; \mathrm{Z}_{\text {exp }}$ : Experimental $\mathrm{ED}_{50}$.

\section{Acknowledgements}

The authors appreciate the efforts of all technical staff of the Department of Biomedical Sciences.

\section{Authors' contributions}

SAO performed all the technical work. SAO, RPB, EO, and EOA performed statistical analysis, prepared most figures, and guided interpretation and drafting of the results. SAO drafted the manuscript and oversaw the editing and revisions. IYA, MAA, and JNB assisted in drafting and reviewing the manuscript. All authors reviewed the final manuscript. All authors read and approved the final manuscript.

\section{Availability of data and materials}

The data are available only upon request from the authors.

\section{Ethics approval and consent to participate}

The activities described here did not include human subjects. All animals were gently handled in all experimental procedures per Animal Welfare Regulations (USDA 1985; US Code, 42 USC § 289d) and the Public Health Service Policy on Humane Care and Use of Laboratory Animals (PHS 2002).

\section{Competing interests}

The authors declare no competing interests in the work described here or the interpretation thereof.

\section{Author details \\ ${ }^{1}$ Department of Biomedical Sciences, School of Allied Health Sciences, Uni- versity of Cape Coast, Cape Coast, Ghana. ${ }^{2}$ School of Pharmacy and Pharma- ceutical Sciences, University of Cape Coast, Cape Coast, Ghana. ${ }^{3}$ Department of Pharmacology, School of Medical Sciences, University of Cape Coast, Cape Coast, Ghana.}

Received: 24 July 2020 Accepted: 19 February 2021

Published online: 25 February 2021

\section{References}

1. WHO. World malaria report 2015. Geneva: World Health Organization; 2016.

2. WHO. World malaria report 2019. Geneva: World Health Organization; 2019.

3. Woodrow CJ, White NJ. The clinical impact of artemisinin resistance in Southeast Asia and the potential for future spread. FEMS Microbiol Rev. 2017:41:34-48.

4. Stewart B, Wild C. World cancer report 2014. Geneva: World Health Organization, International Agency for Research on Cancer; 2015.

5. Coelho CH, Doritchamou JYA, Zaidi I, Duffy PE. Advances in malaria vaccine development: report from the 2017 malaria vaccine symposium. NPJ Vaccines. 2017:2:34

6. Guerin PJ, Olliaro P, Nosten F, Druilhe P, Laxminarayan R, Binka F, et al. Malaria: current status of control, diagnosis, treatment, and a proposed agenda for research and development. Lancet Infect Dis. 2002;2:564-73.

7. Whitty CJ, Staedke SG. Artemisinin-based combination treatment for malaria in Africa: no perfect solutions. Clin Infect Dis. 2005;41:1087-8.

8. Martinelli A, Moreira R, Cravo PV. Malaria combination therapies: advantages and shortcomings. Mini Rev Med Chem. 2008:8:201-12.

9. Dorsey G, Vlahos J, Kamya MR, Staedke SG, Rosenthal PJ. Prevention of increasing rates of treatment failure by combining sulfadoxine-pyrimethamine with artesunate or amodiaquine for the sequential treatment of malaria. J Infect Dis. 2003:188:1231-8.

10. Staedke SG, Kamya MR, Dorsey G, Gasasira A, Ndeezi G, Charlebois ED, et al. Amodiaquine, sulfadoxine/pyrimethamine, and combination therapy for treatment of uncomplicated falciparum malaria in Kampala, Uganda: a randomised trial. Lancet. 2001;358:368-74.

11. Zuber JA, Takala-Harrison S. Multidrug-resistant malaria and the impact of mass drug administration. Infect Drug Resist. 2018;11:299-306.

12. Kaur K, Jain M, Kaur T, Jain R. Antimalarials from nature. Bioorg Med Chem. 2009;17:3229-56.

13. Boampong J, Ameyaw E, Aboagye B, Asare K, Kyei S, Donfack J, et al. The curative and prophylactic effects of xylopic acid on Plasmodium berghei infection in mice. J Parasitol Res. 2013:2013:356107.

14. Ameyaw EO, Asmah KB, Biney RP, Henneh IT, Owusu-Agyei P, Prah J, et al. Isobolographic analysis of co-administration of two plant-derived antiplasmodial drug candidates, cryptolepine and xylopic acid, in Plasmodium berghei. Malar J. 2018;17:153.

15. Abiodun OO, Gbimadee N, Gbotosho GO. Lopinavir/ritonavir enhanced the antimalarial activity of amodiaquine and artesunate in a mouse model of Plasmodium berghei. J Chemother. 2016;28:482-6.

16. Ameyaw EO, Woode E, Boakye-Gyasi E, Abotsi WK, Kyekyeku JO, Adosraku RK. Anti-allodynic and anti-hyperalgesic effects of an ethanolic extract and xylopic acid from the fruits of Xylopia aethiopica in murine models of neuropathic pain. Pharmacogn Res. 2014;6:172-9. 
17. Woode E, Ameyaw EO, Boakye-Gyasi E, Abotsi WK. Analgesic effects of an ethanol extract of the fruits of Xylopia aethiopica (Dunal) A. Rich (Annonaceae) and the major constituent, xylopic acid in murine models. J Pharm Bioallied Sci. 2012;4:291-301.

18. Woode E, Ameyaw EO, Boakye-Gyasi E, Abotsi WKM, Oppong Kyekyeku J, Adosraku R, et al. Effects of an ethanol extract and the diterpene, xylopic acid, of Xylopia aethiopica fruits in murine models of musculoskeletal pain. Pharm Biol. 2016;54:2978-86.

19. Ishih A, Suzuki T, Hasegawa T, Kachi S, Wang H-H, Terada M. In vivo evaluation of combination effects of chloroquine with Cepharanthin ${ }^{\circledR}$ or minocycline hydrochloride against blood-induced chloroquine-resistant Plasmodium berghei NK 65 infections. Trop Med Health. 2004;32:15-9.

20. Williams Al, Rosen FS, Hoff R. Role of complement components in the susceptibility to Plasmodium berghei infection among inbred strains of mice. Ann Trop Med Parasitol. 1975;69:179-85.

21. Dikasso D, Makonnen E, Debella A, Abebe D, Urga K, Makonnen W, et al. In vivo anti-malarial activity of hydroalcoholic extracts from Asparagus africanus Lam. in mice infected with Plasmodium berghei. Ethiop J Health Dev. 2006;20:112-8.

22. Gupta P, Singh L, Singh K. The hybrid antimalarial approach. Annu Rep Med Chem. 2019;53:73-105.

23. Olasehinde $\mathrm{Gl}$, Ojurongbe $\mathrm{O}$, Adeyeba AO, Fagade OE, Valecha N, Ayanda $1 \mathrm{O}$, et al. In vitro studies on the sensitivity pattern of Plasmodium falciparum to anti-malarial drugs and local herbal extracts. Malar J. 2014;13:63.

24. Burrows JN, Duparc S, Gutteridge WE, van Huijsduijnen RH, Kaszubska W, Macintyre F, et al. New developments in anti-malarial target candidate and product profiles. Malar J. 2017;16:26

25. Boakye-Gyasi E, Kasanga EA, Ameyaw EO, Abotsi WKM, Biney RP, Agyare C, et al. An isobolographic analysis of the anti-nociceptive effect of geraniin in combination with morphine or diclofenac. J Basic Clin Physiol Pharmacol. 2018;29:201-9.

26. Miranda HF, Prieto JC, Puig MM, Pinardi G. Isobolographic analysis of multimodal analgesia in an animal model of visceral acute pain. Pharmacol Biochem Behav. 2008;88:481-6.

27. Chou S, Marousek G, Auerochs S, Stamminger T, Milbradt J, Marschall M. The unique antiviral activity of artesunate is broadly effective against human cytomegaloviruses including therapy-resistant mutants. Antiviral Res. 2011;92:364-8.

28. Mishra K, Dash AP, Dey N. Andrographolide: a novel antimalarial diterpene lactone compound from Andrographis paniculata and its interaction with curcumin and artesunate. JTrop Med. 2011;2011:579518.

29. Okoye TC, Akah PA, Ezike AC, Uzor PF, Odoh UE, Igboeme SO, et al. Immunomodulatory effects of Stachytarpheta cayennensis leaf extract and its synergistic effect with artesunate. BMC Complement Altern Med. 2014;14:376.

30. Santos JDO, Pereira GR, Brandão GC, Borgati TF, Arantes LM, Paula RCD, et al. Synthesis, in vitro antimalarial activity and in silico studies of hybrid kauranoid 1,2,3-triazoles derived from naturally occurring diterpenes. J Braz Chem Soc. 2016;27:551-65.

31. Tilley L, Charman SA, Vennerstrom JL. Semisynthetic artemisinin and synthetic peroxide antimalarials. In: Palmer M, Wells T, editors. Neglected diseases and drug discovery. RSC drug discovery series. Cambridge: RSC Pub; 2012. p. 33-64.

32. Asawamahasakda W, Ittarat I, Pu Y-M, Ziffer H, Meshnick SR. Reaction of antimalarial endoperoxides with specific parasite proteins. Antimicrob Agents Chemother. 1994;38:1854-8.

33. Sharma $V$. Therapeutic drugs for targeting chloroquine resistance in malaria. Mini Rev Med Chem. 2005;5:337-51.

34. Osafo N, Obiri DD, Antwi AO, Yeboah OK. The acute anti-inflammatory action of xylopic acid isolated from Xylopia aethiopica. J Basic Clin Physiol Pharmacol. 2018;29:659-69.

35. Osafo N, Biney RP, Obiri DD. Aqueous ethanol fruit extract of Xylopia aethiopica and xylopic acid exhibit anti-inflammatory activity through inhibition of the arachidonic acid pathway. Pharm Biosci J. 2016;4:35-41.

36. Howland SW, Claser C, Poh CM, Gun SY, Rénia L. Pathogenic CD8+ T cells in experimental cerebral malaria. Semin Immunopathol. 2015:37:221-31.

37. Charo IF, Taubman MB. Chemokines in the pathogenesis of vascular disease. Circ Res. 2004;95:858-66.
38. Hezi-Yamit A, Wong PW, Bien-Ly N, Komuves LG, Prasad KS, Phillips DR, et al. Synergistic induction of tissue factor by coagulation factor Xa and TNF: evidence for involvement of negative regulatory signaling cascades. Proc Natl Acad Sci USA. 2005;102:12077-82.

39. Liu Y, Pelekanakis K, Woolkalis MJ. Thrombin and tumor necrosis factor a synergistically stimulate tissue factor expression in human endothelial cells regulation through c-Fos and c-Jun. J Biol Chem. 2004;279:36142-7.

40. Shimizu T, Nishihira J, Watanabe H, Abe R, Honda A, Ishibashi T, et al. Macrophage migration inhibitory factor is induced by thrombin and factor $\mathrm{Xa}$ in endothelial cells. J Biol Chem. 2004;279:13729-37.

41. Helmby H, Cavelier L, Pettersson U, Wahlgren M. Rosetting Plasmodium falciparum-infected erythrocytes express unique strain-specific antigens on their surface. Infect Immun. 1993;61:284-8.

42. Musasia FK. Antibody-mediated clearance of ring-infected erythrocytes as a mechanism of protective immunity against Plasmodium falciparum malaria. Ph.D. Thesis, University of Heidelberg; 2020.

43. Davis R. Cellular and molecular immunology. London: Ed-Tech Press; 2019.

44. Perkins DJ, Were T, Davenport GC, Kempaiah P, Hittner JB, Ong'echa JM. Severe malarial anemia: innate immunity and pathogenesis. Int J Biol Sci. 2011;7:1427-42.

45. Wykes MN, Horne-Debets JM, Leow C-Y, Karunarathne DS. Malaria drives T cells to exhaustion. Front Microbiol. 2014;5:249.

46. Osafo N, Obiri DD. Anti-inflammatory and anti-anaphylactic activity of xylopic acid isolated from the dried fruit of Xylopia aethiopica in mice. Planta Med. 2016;81:S1-381.

47. Mungthin M, Bray PG, Ridley RG, Ward SA. Central role of hemoglobin degradation in mechanisms of action of 4-aminoquinolines, quinoline methanols, and phenanthrene methanols. Antimicrob Agents Chemother. 1998;42:2973-7.

48. Vale PF, MCNally L, Doeschl-Wilson A, King KC, Popat R, Domingo-Sananes $M R$, et al. Beyond killing. Can we find new ways to manage infection? Evol Med Public Health. 2016;2016:148-57.

49. Li C, Sanni LA, Omer F, Riley E, Langhorne J. Pathology of Plasmodium chabaudi chabaudi infection and mortality in interleukin-10-deficient mice are ameliorated by anti-tumor necrosis factor-alpha and exacerbated by anti-transforming growth factor $\beta$ antibodies. Infect Immun. 2003;71:4850-6.

50. Miller LH, Good MF, Milon G. Malaria pathogenesis. Science. 1994;264:1878-83.

51. Segura M, Matte C, Thawani N, Su Z, Stevenson M. Modulation of malariainduced immunopathology by concurrent gastrointestinal nematode infection in mice. Int J Parasitol. 2009;39:1525-32.

52. Thien HV, Kager PA, Sauerwein HP. Hypoglycemia in falciparum malaria: is fasting an unrecognized and insufficiently emphasized risk factor? Trends Parasitol. 2006;22:410-5.

53. Coban C, Lee MSJ, Ishii KJ. Tissue-specific immunopathology during malaria infection. Nat Rev Immunol. 2018;18:266.

54. Alyousif MS, Saifi MA, Ahmed M, Alouysif S. Histopathological changes induced by artesunate in liver of Wistar rat. Int J Pharmacol. 2017:13:104-8.

55. Lind D, Levi J, Vincent P. Amodiaquine-induced agranulocytosis: toxic effect of amodiaquine in bone marrow cultures in vitro. BMJ. 1973;1:458-60

56. Tang Y, Wu Q, Beland FA, Chen S, Fang J-L. Apoptosis contributes to the cytotoxicity induced by amodiaquine and its major metabolite $\mathrm{N}$-desethylamodiaquine in hepatic cells. Toxicol In Vitro. 2020;62:104669.

57. Angus B. Novel anti-malarial combinations and their toxicity. Expert Rev Clin Pharmacol. 2014;7:299-316.

58. Khera A, Mukherjee R. Artemisinin resistance: cause for worry? J Mar Med Soc. 2019;21:4-8.

\section{Publisher's Note}

Springer Nature remains neutral with regard to jurisdictional claims in published maps and institutional affiliations. 